\title{
Desigualdad, pobreza y futuro
}

\section{Ramón Barinaga}

Asociación Guipuzcoana de Autismo (Gautena)

<direccion@gautena.org>

Ikuspegi etiko bat eta zenbait egileren ekarpenak bilduz, artikulu honetan gogoeta burutzen da desberdintasun, pobrezia eta ondasun komunaz; eta zenbait proposamen aurkezten dira planetako biztanleentzat etorkizunerako justizia sozialaren teoria berri bat artikulatzeko premiaz.

\section{HITZ-GAKOAK:}

Desberdintasuna, pobrezia, ondasun komuna, iraunkortasuna, etika, etorkizuna.
Desde una perspectiva ética y a partir de las aportaciones de diferentes autores, este artículo reflexiona sobre la desigualdad, la pobreza y el bien común, y plantea una serie de propuestas de futuro a partir de la necesidad de articular una nueva teoría de la justicia social para todos los habitantes del planeta.

Palabras ClaVe:

Desigualdad, pobreza, bien común, sostenibilidad, ética, futuro. 


\section{Introducción}

El logro de sociedades más igualitarias es un objetivo generalmente aceptado del desarrollo. Sin embargo, al comienzo de la segunda década del siglo XXI, mil cuatrocientos millones de personas viven en la extrema pobreza, y el diferencial entre los más ricos y los más pobres se acrecienta de modo nunca antes conocido. Adicionalmente, la 'gran contracción' que aqueja a buena parte de las economías avanzadas incrementa las diferencias en el interior de los países, impulsando a sectores de la clase media hacia diversas formas de exclusión social.

Este artículo, sin abordar el análisis de la desigualdad en el interior de los países, se aproxima a aspectos clave concernidos al tomar en cuenta la cuestión de la desigualdad y la pobreza a escala planetaria, a partir del análisis de diversos autores que reflexionan desde la economía, la filosofía y la política. Las aportaciones principales de estos autores van desde la necesidad de articular una nueva teoría de la justicia social para todos los habitantes del planeta, a la identificación de las circunstancias que hacen que unos países prosperen en el tiempo y sean políticamente estables frente a las de los que no lo hacen, pasando por una llamada a retomar la sabiduría de ciertas tradiciones económicas y sociales en la conformación de sociedades justas y socialmente cohesionadas, hasta llegar a la apelación a la respuesta individual en la lucha contra la pobreza en el mundo.

\section{Hacia una nueva teoría de la justicia social}

En Las fronteras de la justicia: consideraciones sobre la exclusión (2006), Martha C. Nussbaum, profesora de Ética y Derecho en la Universidad de Chicago y premio príncipe de Asturias de ciencias sociales 2012, plantea la necesidad de disponer de una teoría de la justicia social que supere la del contrato social, incorporando tres dominios en las que ésta, en su opinión, falla. Esos tres ámbitos son los siguientes: en primer lugar, el problema de la justicia hacia las personas con discapacidades físicas y mentales; en segundo, el problema urgente de extender la justicia a todos los ciudadanos del mundo, de desarrollar un modelo teórico de un mundo justo en su totalidad, donde los accidentes de nacimiento y de origen no vicien desde el principio y en todos los sentidos las opciones vitales de las personas; y en tercero, las cuestiones de justicia relacionadas con el trato que dispensamos a los animales no humanos.

\subsection{Más allá del contrato social}

Para Nussbaum, "la idea de que los principios políticos básicos son el resultado de un contrato social es una de las grandes contribuciones de la filosofía política liberal a la tradición occidental. En la medida en que el punto de partida fuera equitativo [...], los principios resultantes de dicha negociación serán también equitativos. Las diversas teorías del contrato social nos han legado una imagen general de la sociedad como un contrato orientado al beneficio mutuo (las personas obtienen algo de su vida en común que no obtendrían viviendo por separado) entre personas libres, iguales e independientes".

Sin embargo, en opinión de esta autora, en un mundo cada vez más interdependiente no podemos ignorar los principios de justicia planteados por las desigualdades entre los países ricos y pobres, que afectan a las oportunidades de vida de sus ciudadanos. El modelo del contrato social sirve habitualmente para construir una sociedad que se pretende autosuficiente y no interdependiente con otras sociedades. Pero, añade: "Es dudoso que tenga sentido partir de la independencia y la igualdad aproximada de los Estados en un mundo marcado por una poderosa economía global que vuelve interdependientes todas las elecciones económicas, y que a menudo impone a los países pobres condiciones que refuerzan y agravan las desigualdades existentes".

Las teorías clásicas del contrato social adoptan un enfoque débil sobre las relaciones internacionales, centradas en las cuestiones relativas a la guerra y la paz, y se niegan a entrar en cuestiones de redistribución económica o de protección de los derechos humanos básicos. Nos recuerda Nussbaum que Hugo Grocio, en el siglo XVII, ya había sostenido que una paz no sería duradera si ignoraba la necesidad de una redistribución económica. Y sentencia: "Este enfoque débil caracteriza hoy las prácticas de los países ricos y nuestros sistemas de derecho internacional, y cada vez se muestra más inadecuado para el mundo en que vivimos. Una reflexión crítica sobre las operaciones del sistema económico global, que es controlado por un reducido número de países, pero tiene un impacto decisivo sobre todos los demás, plantea cuestiones de justicia urgentes de cara al futuro".

\subsection{El enfoque de las capacidades}

La autora norteamericana propone un enfoque alternativo a partir de la idea de las capacidades. Su idea es que existe un enfoque de las cuestiones de justicia básica que puede llevarnos más lejos que las doctrinas del contrato social. El enfoque de las capacidades, desarrollado por Nussbaum en filosofía y por Amartya Sen en economía, se presenta así como la fuente de los principios políticos para una sociedad liberal y pluralista; su contexto es un tipo de liberalismo político que los convierte en fines específicamente políticos y los formula de un modo que evita toda fundamentación metafísica específica: "Así presentadas y defendidas argumentativamente, las capacidades pueden dar lugar, en mi opinión, a un consenso entrecruzado entre personas que de otro modo tendrían unas concepciones comprehensivas del bien muy distintas".

El enfoque de las capacidades es una concreción del enfoque de los derechos humanos, los cuales han 
sido asociados a la idea de la dignidad humana: “La idea intuitiva básica de mi versión del enfoque de las capacidades es que debemos partir de una concepción de la dignidad del ser humano y de una vida acorde con esa dignidad. Partiendo de esta idea básica, pretendo justificar una lista de diez capacidades como requisitos básicos para una vida digna. Todas ellas forman parte de una teoría mínima de la justicia social: una sociedad que no las garantice a todos sus ciudadanos, en un nivel mínimo adecuado, no llega a ser una sociedad plenamente justa, sea cual sea su nivel de opulencia”.

Las capacidades formuladas por Nussbaum son las siguientes:

- Vida: poder vivir hasta el término de una vida humana de duración normal.

- Salud física, que incluye alimentación y disponer de un lugar adecuado para vivir.

- Integridad física: libertad de movimientos, estar libre de agresiones sexuales y violencia doméstica.

- Sentidos, imaginación y pensamiento, que incluye alfabetización y formación, libertad de expresión, política y religiosa.

- Emociones: poder mantener relaciones afectivas, desarrollo emocional.

- Razón práctica, que se refiere a poder formarse una concepción del bien y tener un plan de vida.

- Afiliación: poder vivir con y para los otros, autorrespeto y no humillación.

- Otras especies: relación respetuosa con animales, plantas y el mundo natural.

- Juego: poder reír, jugar y disfrutar de actividades recreativas.

- Control sobre el propio entorno político (a través de la participación, libertad de expresión y asociación) y material (poder disponer de propiedades, poder trabajar como un ser humano).

"Creo que podemos justificar que esta lista es una buena base para establecer unos principios políticos para todo el mundo", señala Nussbaum.

\subsection{Una teoría de los derechos políticos fundamentales}

En Crear capacidades: propuesta para el desarrollo humano (2011), Nussbaum formula la pregunta clave que cabe hacerse cuando se comparan sociedades y se evalúan conforme a su dignidad y a su justicia básicas: ¿qué es capaz de hacer y de ser cada persona? El enfoque concibe cada persona como un fin en sí misma y no se pregunta solamente por el bienestar total o medio, sino también por las oportunidades disponibles para cada ser humano. Está centrado en la elección o en la libertad, pues defiende que el bien crucial que las sociedades deberían promover para sus pueblos es un conjunto de oportunidades (o libertades sustanciales) que las personas pueden luego llevar, o no, a la práctica: ellas eligen. Es, por lo tanto, un enfoque comprometido con el respeto a las facultades de autodefinición de las personas y decididamente pluralista en cuanto a valores.

La teoría de las capacidades asigna una tarea urgente al Estado y a las políticas públicas: la de mejorar la calidad de vida para todas las personas, una calidad de vida definida por las capacidades de éstas. La teoría de las capacidades se constituye, así, en una teoría de los derechos políticos fundamentales.

Para esta profesora de Ética, vivimos en una era dominada por el afán de lucro y por la preocupación por los logros económicos nacionales. Pero el crecimiento económico, aun siendo un elemento de una política pública sensata, no es más que una parte y un instrumento de ésta. Son las personas quienes importan en última instancia; los beneficios económicos constituyen solamente medios instrumentales para las vidas humanas, que son sus fines. La finalidad del desarrollo global -como la finalidad de una buena política a escala nacional- consiste en hacer posible que las personas lleven vidas plenas y creativas, desarrollen su potencial y lleven una existencia significativa, acorde con la igualdad de dignidad humana de todos los individuos. Dicho de otro modo, el propósito real del desarrollo es el desarrollo humano.

\subsection{Reciprocidad y papel de las instituciones en la benevolencia y la generación de actitudes}

Nussbaum argumenta de la siguiente manera: “Es muy probable que los cambios que debamos introducir para llevar la justicia a los países en vías de desarrollo, y a las personas con graves deficiencias que viven en nuestro propio país, sean caros y no se puedan justificar desde la perspectiva del beneficio mutuo. Peor para nosotros. La justicia es uno de nuestros fines, y la reducimos demasiado cuando la concebimos como el resultado de un contrato para el beneficio mutuo, por más especificaciones y condiciones morales que introduzcamos. También nos reducimos a nosotros mismos cuando imaginamos la reciprocidad como algo que sólo puede darse entre seres aproximadamente iguales, capaces de ofrecerse un beneficio mutuo".

El enfoque de las capacidades es muy exigente con los seres humanos. Demanda de ellos mucho más que las teorías clásicas del contrato social y un poco más que lo que Rawls exigía a los ciudadanos de la "sociedad bien ordenada", aun cuando las exigencias de este autor eran ya muy sustanciales. La solución de nuestros tres problemas no resueltos pasa necesariamente por que las personas hagan gala de una solidaridad y de una benevolencia muy grandes, y mantengan esos sentimientos a lo largo del tiempo.

Como en el caso de Rawls, también desde este enfoque las instituciones desempeñan un papel muy 
importante a la hora de estabilizar la benevolencia y, en el fondo, de articular una concepción adecuadamente definida de lo que tal benevolencia exige. Pero las instituciones no se crean si las personas no las quieren y pueden cesar de existir si ya no interesan a la gente, algo que el declive de la democracia social inspirada por el New Deal en Estados Unidos ha demostrado con total claridad.

Para Nussbaum, "La estabilidad de la sociedad justa depende de la capacidad que tenga de inculcar las actitudes y los sentimientos correctos en las personas para que éstas se muestren favorables a cambios de gran alcance en la distribución existente de bienes". Para todos aquellos que den por sentado que la ventaja mutua es el único aglutinante posible de una cultura política liberal, seguiremos calificando cínicamente de 'utópicos' proyectos como el que yo propongo para las tres áreas fronterizas de la justicia”.

\section{Factores determinantes en la generación sostenible de riqueza}

En Por qué fracasan los países: los orígenes del poder, la prosperidad y la pobreza (2012), Daron Acemoglu, profesor de Economía en el Massachusetts Institute of Technology (MIT), y James A. Robinson, politólogo, economista y profesor en la Universidad de Harvard, ofrecen un interesante análisis sobre la desigualdad en el mundo, que tiene por objeto "su comprensión a escala planetaria, como primer paso para generar ideas sobre cómo mejorar la vida de miles de millones de personas que todavía viven en la pobreza”.

\subsection{Historia y economía}

Estos autores muestran que la mayoría de las enormes diferencias económicas que observamos a nuestro alrededor hoy día surgieron durante los últimos doscientos años. Como explican en su libro, "cada sociedad funciona con una serie de reglas políticas y económicas creadas e impuestas por el Estado y los ciudadanos colectivamente. Las instituciones económicas dan forma a los incentivos económicos. Los incentivos para recibir una educación, ahorrar e invertir, innovar y adoptar nuevas tecnologías, etc. Es el proceso político lo que determina bajo qué instituciones se vivirá y son las instituciones políticas las que determinan cómo funciona este proceso".

Por ejemplo, las instituciones políticas de una nación determinan la capacidad de los ciudadanos de controlar a los políticos e influir en su comportamiento. Esto, a su vez, determina si los políticos son agentes (aunque sea imperfectos) de los ciudadanos, o si son capaces de abusar del poder que se les confía o que han usurpado, para amasar sus propias fortunas y seguir sus objetivos personales en detrimento de los de los ciudadanos.

Las instituciones políticas incluyen a menudo constituciones escritas, y en democracia, incluyen la capa- cidad y el poder del Estado para regular y gobernar la sociedad. También es necesario considerar más ampliamente los factores que determinan cómo se reparte el poder político en la sociedad, sobre todo la capacidad de los distintos grupos de actuar colectivamente para conseguir sus objetivos e impedir que otras personas consigan los suyos.

\subsection{Las instituciones políticas y económicas inclusivas son la clave de bóveda de un desarrollo sostenible}

En su libro demuestran que, "aunque las instituciones económicas sean críticas para establecer si un país es pobre o próspero, son la política y las instituciones políticas las que determinan las instituciones económicas que tiene un país. Nuestra teoría para explicar la desigualdad mundial señala cómo interactúan las instituciones políticas y económicas para crear pobreza o prosperidad, y cómo las distintas partes del mundo acabaron con conjuntos de instituciones tan distintos".

Añaden que "los distintos modelos de las instituciones actuales están profundamente arraigados en el pasado, porque, una vez que una sociedad se organiza de una forma concreta, ésta tiende a persistir. Esta persistencia y las fuerzas que la crean también explican por qué es tan difícil eliminar la desigualdad mundial y hacer que los países pobres sean prósperos. La dificultad proviene del hecho de que los intereses encontrados no facilitan el consenso preciso para modificar las cosas, aun a sabiendas de que el cambio en las instituciones políticas y en la interacción de éstas con las económicas es la piedra angular del cambio y del desarrollo igualitario".

Su teoría establece dos tipos de análisis: distingue entre instituciones políticas y económicas extractivas e inclusivas, y explica por qué surgieron instituciones inclusivas en algunas partes del mundo y no en otras. Su gran aportación es demostrar que "es en la confluencia de instituciones económicas inclusivas que hacen respetar los derechos de propiedad, crean igualdad de oportunidades y fomentan la inversión en habilidades y nuevas tecnologías, y de instituciones políticas inclusivas, es decir, las que reparten el poder político ampliamente de manera pluralista y son capaces de lograr cierto grado de centralización política para establecer la ley y el orden, donde se van a dar las condiciones para un desarrollo más sólido y estable y que llegue a más personas". Uno a uno, descartan otros pretendidos argumentos, como los que hacen referencia a la hipótesis geográfica, o la cultura.

\subsection{El cambio institucional, a fondo}

Para estos autores, "el cambio institucional a fondo, el requisito para que se produzca un gran cambio económico, tiene lugar como resultado de la interacción entre las instituciones existentes y las coyunturas críticas. Las coyunturas críticas son grandes aconteci- 
mientos que perturban el equilibrio político y económico existente en una o muchas sociedades, como por ejemplo, la peste negra en la Europa del siglo XIV, la apertura de las rutas de comercio atlántico tras el descubrimiento de América y la revolución industrial”.

La teoría de estos autores trata de cómo los países pueden dar pasos hacia la prosperidad, transformando sus instituciones de extractivas en inclusivas. Aunque no dice que sea fácil que tal modificación se produzca, ya que los modelos extractivos se pueden recrear adoptando distintas formas. Y añaden: “Intentar diseñar prosperidad sin abordar la raíz de la causa de los problemas (instituciones extractivas y la política que las mantiene en vigor) es poco probable que dé frutos. Lo que tienen en común las revoluciones políticas que lograron allanar el camino para las instituciones más inclusivas [...] es que lograron conferir poder a una parte bastante amplia de la sociedad. El pluralismo, el fundamento de las instituciones políticas inclusivas, implica que el poder político esté ampliamente repartido en la sociedad, y para las instituciones extractivas que conceden el poder a una reducida élite, esto exige una cesión de poderes".

En ese complejo proceso de cambio de instituciones extractivas a inclusivas, estos autores señalan el papel que pueden desempeñar los medios de comunicación en la movilización de un segmento amplio de la sociedad.

\subsection{El círculo virtuoso}

De la misma forma que las instituciones extractivas tiene alta capacidad de recrearse, estos autores consideran que, una vez instauradas, "las instituciones políticas y económicas inclusivas tienden a crear un círculo virtuoso, un proceso de retroalimentación positiva, lo que aumenta la probabilidad de que estas instituciones persistan e incluso se expandan". El círculo virtuoso funciona a través de varios mecanismos:

- Por un lado, la lógica de las instituciones políticas pluralistas hace que la usurpación del poder sea más difícil. Asimismo, el pluralismo consagra la noción de Estado de derecho, el principio de que las leyes deben aplicarse a todos por igual, y abre la puerta a una mayor participación en el proceso político y a una mayor inclusividad.

- Por otro lado, las instituciones políticas inclusivas son apoyadas por instituciones económicas inclusivas. Así, las instituciones económicas inclusivas eliminan las relaciones económicas extractivas más atroces, como la esclavitud y la servidumbre, reducen la importancia de los monopolios y crean una economía dinámica.

- Finalmente, las instituciones políticas inclusivas permiten que florezcan medios de comunicación libres, que a menudo proporcionan información y movilizan a la oposición frente a la amenaza contra las instituciones inclusivas.

\section{Recuperar la sabiduría de cierta tradición económica y social}

Robert Skidelsky, catedrático emérito de Economía Política en la Universidad de Warwick, y Edward Skidelsky, profesor de Filosofía en la Universidad de Exeter, ambas en el Reino Unido, en ¿Cuánto es suficiente?: qué se necesita para una buena vida (2012), pretenden contribuir a que hagamos un replanteamiento de lo que queremos de la vida; para qué sirve el dinero y qué significa 'buena vida'.

\subsection{La buena vida: una vida deseable}

En su opinión, hasta hace poco las políticas públicas en el mundo occidental han tomado forma a partir de ideas de la buena vida y de la buena sociedad. "Sólo haría falta un atisbo de coraje político para restablecerlas a su posición central”, sostienen. En este sentido, "ha sido necesario recuperar ideas filosóficas y éticas que, aunque hace tiempo que ya no están en boga, están lejos de haber desaparecido. Las personas se sienten, en realidad, bastante divididas en lo que respecta a su ética. La mayor parte de los banqueros de la City de Londres admiten que sus sueldos son excesivos, y que los de los médicos y maestros son demasiado bajos". Y añaden: "Las personas que aspiran a hacerlo lo mejor posible dentro del sistema imperante pueden, no obstante, aspirar a vivir en un sistema mejor".

Para ello, proponen un repaso de las aportaciones del pensamiento económico y social en la historia, de la doctrina social de la iglesia católica, de la economía social de mercado surgida en la Alemania antinazi de los cuarenta, del neoliberalismo de Keynes, Beveridge y Roosevelt, y de la socialdemocracia, a los que se contrapone el capitalismo darwiniano iniciado con Thatcher y Reagan en los ochenta y hoy dominante, para acabar señalando la caída del comunismo como "golpe de gracia" a las interpretaciones de la búsqueda del bien común: "Nuestra tarea es, pues, recuperar los fragmentos de sabiduría que siguen existiendo, ya sea en tradiciones pasadas o en las nuestras propias, y profundamente arraigadas, intuiciones, para reconstruir a partir de ellos una imagen de la buena vida. Si podemos lograrlo, quizá podamos recuperar, en una forma democrática, si no su vigor creativo, sí parte de la douceur de las grandes civilizaciones de antaño".

\subsection{Bienes básicos}

Para estos autores, nuestra adicción al consumo y al trabajo se debe, sobre todo, a la desaparición de cualquier idea acerca de la buena vida en el debate público. Para volver a comprender lo que significa tener suficiente, debemos aprender de nuevo a formular la pregunta ¿qué significa vivir bien?: "La buena vida es una vida deseable, o digna de ser deseada, no sólo una vida ampliamente deseada. No podemos identificarla contando votos o pasando 
cuestionarios. Pero la buena vida tampoco puede ser radicalmente distinta de las aspiraciones de la mayoría de personas a lo ancho del mundo y a lo largo del tiempo [...], porque la materia de la que trata la ética, el bien humano, es algo acerca de lo que todos los seres humanos tienen algo que decir".

Hay un amplio acuerdo "en lo que podríamos denominar 'bienes básicos', aquellos que constituyen la buena vida: salud, respeto, seguridad, relaciones de confianza y amor. Discrepan de Sen y Nussbaum en cuanto que, para ellos, los bienes básicos, no son solamente medios o capacidades para la buena vida, son la buena vida, la meta apropiada de la acción privada y de la acción política. Para estos autores los bienes básicos reúnen cuatro características: son universales - pertenecen a la buena vida como tal-, finales -buenos por sí mismos-, sui géneris -no forman parte de ningún otro bien-e indispensables -se puede considerar que aquel que carezca de ellos ha sufrido una pérdida o un daño graves-. A partir de estas cuatro características, identifican siete bienes básicos: salud, seguridad, respeto, personalidad -la capacidad de formular y ejecutar un plan de vida que refleje el gusto, temperamento y concepto del bien propios-, armonía con la naturaleza, amistad y ocio -lo que hacemos por el propio hecho de hacerlo, no como medio para otra cosa-.

\subsection{Papel del Estado}

En relación al papel del Estado, sostienen que "si el primer objetivo del individuo es hacer realidad la buena vida para sí mismo, el primer deber del Estado es hacer realidad, dentro de sus posibilidades, la buena vida para todos los ciudadanos [...]. El Estado desarrolla un papel importante y legítimo en crear las condiciones materiales dentro de las cuales estos otros bienes pueden prosperar".

Tales condiciones no sólo incluyen un cierto nivel general de riqueza nacional, sino una justa distribución de ésta, prudencia en el gasto público y muchos otros factores. El resto se halla en las manos de las personas y de las instituciones civiles. Parafraseando a Keynes, el Estado no tiene en sus manos la civilización, sino la posibilidad de civilización: "El deber esencial del Estado es la creación de las condiciones materiales para que todos puedan gozar de una buena vida”.

“¿Y dónde queda entonces el crecimiento?”, se preguntan estos autores: "El crecimiento -explicantiene sentido como medio para el logro de los bienes básicos, y no como objetivo en sí mismo. Los bienes básicos son cualitativos, no cuantitativos, objetos de criterio, no de medida. Así, cuando se miden, por ejemplo, los ingresos per cápita en Gran Bretaña, se ve que éstos se han más que duplicado desde 1974. Sin embargo, durante ese mismo periodo, los bienes básicos no han crecido en absoluto, o incluso se han atrofiado. Otras naciones ricas muestran una imagen más variada".

\subsection{El error de la profecía de Keynes}

Keynes erró en su profecía al anticipar que, en un siglo (desde la década de los treinta del pasado siglo), el ser humano podría alcanzar una situación en la que, gracias al progreso tecnológico, podría trabajar menos horas, con lo que, "por primera vez en la historia, el hombre se enfrentaría a su problema real y permanente: cómo utilizar su libertad desde la presión de los apuros económicos, cómo ocupar el tiempo de ocio, que la ciencia y el interés compuesto le habrán proporcionado, para vivir bien, sabiamente, y de forma agradable".

Skidelsky y Skidelsky plantean la siguiente pregunta: “¿De qué recursos intelectuales, morales y políticos disponemos aún en las sociedades occidentales para invertir el asalto de la insaciabilidad y redirigir nuestros propósitos hacia la buena vida?". En respuesta a ella, subrayan la necesidad de salir de la competitividad febril del actual modo de organización social y económica, y se preguntan "¿cómo puede una sociedad que ya tiene 'suficiente' pensar acerca de la organización de su vida colectiva?”. Su intención es, más bien, desviar las convenciones sociales hacia la buena vida, hacer que las personas puedan organizar con mayor facilidad sus propias salidas de la competitividad ansiosa, descubriendo, por ejemplo, formas de vida en las que ganar dinero no sea la cuestión principal.

Por otro lado, alertan de que "ningún sistema político o legal puede evitar la parcialidad, por mucho que proclame su neutralidad". Piden que "el Estado haga sus elecciones éticas de forma explícita, para poder mantener un verdadero debate moral". Valoran la, en su opinión, muy probable alta influencia del impulso religioso en la búsqueda del bien común.

Y señalan que "piensen lo que piensen los lectores acerca de nuestras sugerencias, las sociedades ricas ya no se pueden permitir el dejar de desarrollar una visión colectiva de la buena vida y deambular sin un esquema sobre la verdadera utilidad de la riqueza. El mayor despilfarro al que nos enfrentamos ahora no es de dinero, sino de posibilidades humanas".

\section{Respuesta individual en la lucha contra la pobreza}

Peter Singer, profesor de Bioética en la Universidad de Princeton (EE.UU.), plantea en su libro Salvar una vida: cómo terminar con la pobreza (2012) un alegato a favor de considerar las obligaciones de cada persona con respecto a aquellas que viven sumidas en la pobreza.

\subsection{Algunos datos sobre la pobreza}

Señala Singer: "El número de muertes provocadas por el hambre de los últimos veinte años supera el de las causadas durante el siglo XX por el conjunto 
de las guerras y la represión de todos los Gobiernos, incluidos el de Hitler y el de Stalin. Vivimos en un mundo en el que cada año mueren por hambre o causas evitables 18 millones de personas". Según datos de Unicef, cada año mueren casi 10 millones de niños menores de 5 años por causas relacionadas con la pobreza.

Por su parte, el Banco Mundial define la pobreza extrema como aquella situación en la que no se tienen ingresos suficientes para satisfacer las necesidades humanas más básicas, como una alimentación adecuada, agua, cobijo, ropa, higiene, atención sanitaria y educación. Según el Banco Mundial (datos de 2008), el umbral de pobreza se establece en 1,25 dólares diarios, habiendo 1.400 millones personas que se sitúan en ese grado de pobreza extrema. Junto a esos 1.400 millones de personas en pobreza extrema, hay otros 1.000 millones de habitantes que viven con un nivel de prosperidad jamás conocido anteriormente, salvo en las cortes de los reyes y los aristócratas. Para Singer, en el mundo "hay mil millones de personas en situación de salvar a los diez millones de niños que mueren anualmente por causas relacionadas con la pobreza".

\subsection{Razonamiento moral para la ayuda y argumentos para la inacción}

Singer nos propone un razonamiento moral según el cual no vacilaríamos en salvar la vida de un niño que se estuviera ahogando en un estanque poco profundo, y que lo haríamos aun cuando nos supusiera un esfuerzo considerable. Pero gastamos dinero en cosas que damos por sentadas y en las que apenas repararíamos si, al mismo tiempo, no murieran miles de niños a diario. En opinión de Singer, esta forma de actuar es moralmente reprobable y analiza hasta dónde llegan nuestras obligaciones para con los pobres.

Pensar desde el punto de vista ético consiste en ponerse en el lugar de los demás; por ejemplo, en el de los padres de ese niño, o en el del propio niño. La idea se resume en la regla de oro de la ética de la reciprocidad: 'Trata a los demás como te gustaría ser tratado'. Singer señala que, si bien para la mayoría de los occidentales la ética de la reciprocidad es más célebre por las palabras de Jesús tal como las recogen Mateo y Lucas, se trata en realidad de una ética extraordinariamente universal que podemos encontrar en todas las religiones. La ética de la reciprocidad exige que aceptemos que los deseos de los demás deben tenerse en cuenta como si fueran propios.

Singer examina con datos que la ayuda de los países ricos al desarrollo es muy corta y está mal dirigida - desde el punto de vista de un adecuado fomento del desarrollo-. Este autor defiende su tesis de la crítica de "quietismo político" que le hace el filósofo Paul Gomberg, que dice que este tipo de visión propone una filantropía “que desvía la atención de las causas institucionales de la pobreza (en esencia, y a su juicio, el capitalismo) y de la necesidad de buscar alternativas radicales a las instituciones que la producen”. Singer se pregunta por qué las personas no hacen más por los demás que lo que hacen, y qué podría impulsarlas a hacer más. ¿Por qué no salvamos la vida de los niños de los países en vías de desarrollo si el coste de hacerlo es tan reducido (entre 200 y 3.000 dólares, según reconocidos estudios)? Éstas son las razones por él analizadas.

En primer lugar, actuamos en función del efecto 'víctima identificada' que desemboca en la 'regla del rescate': invertiremos mucho más en rescatar a una víctima identificada que en salvar una 'vida estadística'. En segundo lugar, analiza el factor 'provincianismo', según el cual prestamos atención a los más próximos y afines. Tras analizar las reflexiones que en el tiempo han apoyado esta idea, las critica señalando que, en la actualidad, tenemos una gran y efectiva capacidad de ayudar a personas en lugares remotos, por el desarrollo de las comunicaciones, los transportes y por la capacidad económica de los habitantes de los países ricos respecto a los de los más pobres. En tercer lugar, analiza el 'sentimiento de futilidad', la idea de que "las cosas no van a cambiar", de que "nunca habrá suficiente dinero para ayudar a todas esa gente". El pensamiento de futilidad plantearía que la ayuda a los pobres representa "un grano de arena en el desierto", con lo que presuponemos que no vale la pena prestarla, ya que, por mucho que hagamos, el desierto de necesitados seguirá pareciendo tan inmenso como antes. Por último, otro ‘motivo' que impulsa a la inacción sería el de la 'disolución de la responsabilidad', que se produce cuando entendemos que la responsabilidad no recae enteramente sobre nosotros, y lleva al 'efecto espectador'.

\section{3. ¿Ayudar sobre todo a los próximos y afines?}

Singer sabe que la solidaridad es más fuerte entre afines: "Tal vez el hecho de que tengamos tendencia a favorecer a nuestra familia, a nuestra comunidad y a nuestro país explique la incapacidad para salvar la vida de los pobres que viven más allá de dichas fronteras, pero no lo justifica desde una perspectiva ética, independientemente de cuántas generaciones de antepasados nuestros no hayan visto nada malo en ello".

Continúa señalando que, "tal vez, las pautas de conducta que sirvieron para que nuestros antepasados sobrevivieran y se reprodujeran no nos sirvan de nada a nosotros, ni a nuestros descendientes, en las muy distintas circunstancias de la actualidad. De cualquier modo, aun cuando alguna intuición o forma de actuar evolutiva siguiera permitiéndonos sobrevivir y reproducirnos, ese hecho no lo convertiría en correcto, como reconocía el propio Darwin, para quien la evolución no tiene sentido moral".

Singer propone actuar y donar a favor de los pobres: "Como no se ha intentado nunca, nadie sabe en 
realidad si es posible vencer a la pobreza a escala mundial suministrando dosis de ayuda verdaderamente sustanciales y sin interferencias políticas. Las limitaciones políticas y burocráticas que obstaculizan la ayuda oficial redoblan la importancia de realizar donaciones particulares a las agencias no gubernamentales que han demostrado su eficiencia”.

La cifra total de la ayuda anual para las aproximadamente 3.000 millones de personas pobres del mundo (este dato incluye a quienes viven con menos de 2 dólares diarios, y no sólo a quienes subsisten con menos de 1,25 dólares) se reduce a unos 20 dólares por persona. Por ello se pregunta: “¿Debe sorprendernos que esta mísera suma no haya acabado con la pobreza? Lo máximo que puede decirse, sin el menor género de duda, es que, en el pasado, mucha ayuda oficial ha sido equivocada, desviada o ha servido para muy poco. Pero si se hacen las cosas bien y con el debido dimensionamiento, parece poco verosímil que seamos incapaces de encontrar formas que producirán un efecto positivo".

El mejor modo de ayudar a los pobres es el de la ayuda concebida para mejorar la producción local de alimentos, y ofrecer educación y atención sanitaria básica. En condiciones ideales, la ayuda debería proporcionar un colchón de seguridad, para quienes no se benefician del crecimiento económico. La idea de que las buenas instituciones desempeñan un papel esencial en la reducción de la pobreza no conduce a negar el valor de la ayuda, sino más bien a condicionarla a que el Gobierno receptor desempeñe sus funciones para establecer el marco del crecimiento económico.

\subsection{Una propuesta de escala de aportaciones y su impacto real}

Singer, a modo de propuesta de trabajo, plantea una escala de donación estimada para la situación en Estados Unidos, que se aplicaría a partir de 100.000 dólares de ingresos anuales, empezaría en un $5 \%$ y tendría carácter progresivo. Según dicha escala, que establece un nivel de aportación que parece muy razonable en el contexto fiscal de aquel país, sólo con las donaciones del $10 \%$ más rico de los estadounidenses se recaudarían al año 471.000 millones de dólares (recordemos que, para alcanzar los Objetivos del Milenio de Naciones Unidas, se calculaba que harían falta, como máximo, 189.000 millones de dólares anuales).

Generalizar esta escala al conjunto del mundo (rico) reportaría más de un billón y medio de dólares anuales para ayuda al desarrollo. La cifra es ocho veces superior a la que el grupo de trabajo de la ONU estimó necesaria para cumplir los Objetivos de Desarrollo del Milenio antes de 2015, y equivale a veinte veces el déficit entre la suma que estimó y los compromisos de ayuda oficial al desarrollo existentes en la actualidad. La meta que deberíamos fijarnos no es reducir a la mitad la proporción de personas que viven en la pobreza extrema o sin suficiente alimento, sino garantizar que nadie tenga que vivir para siempre en unas condiciones tan degradantes. "El objetivo es asequible", concluye Singer.

La mayoría preferimos la armonía a la discordia, ya sea entre unos y otros, o en nuestro interior. Esa armonía interior se ve amenazada por cualquier discrepancia palmaria entre el modo en que vivimos y aquel en que creemos que deberíamos vivir. Nuestro raciocinio puede decirnos que deberíamos estar haciendo algo sustancial para ayudar a los más pobres del mundo, pero tal vez las emociones no puedan impulsarnos a actuar en consonancia con dicha opinión. Y añade Singer: "Si a usted lo convence el razonamiento moral, pero no consigue motivación suficiente para actuar en consecuencia, le recomiendo que haga algo que sea significativamente más relevante que lo que ha hecho hasta este momento. Luego, vea qué tal se siente. Tal vez le resulte más reconfortante de lo que imaginaba".

\section{Ideas de cara al futuro}

La realidad de la desigualdad en el mundo, con sus manifestaciones de extrema pobreza, pobreza, y de acumulación de cada vez mayor riqueza en menos manos, supone un problema al mismo tiempo ético, económico y político. Y, como dice Joseph Stiglitz, catedrático de Economía en la Universidad de Columbia y premio nobel de Economía en El precio de la desigualdad (2012), "no tiene sentido hacer como si nada”. Repasaremos brevemente las aportaciones de este autor, $y$, junto con las de algunos otros que ya se han mencionado, trataremos de proponer algunas ideas para abordar estas cuestiones.

\subsection{Hacia una teoría de los derechos políticos fundamentales}

Desde el punto de vista de la argumentación filosófica que constituye la base de los derechos políticos, parece claro que necesitamos una nueva aproximación que contemple la complejidad e interrelación de un mundo que requiere algo más que las teorías clásicas sobre la justicia social que hasta ahora han permitido su modelización. En este camino, Martha C. Nussbaum $(2006,2011)$ propone avanzar desde las teorías clásicas del contrato social hacia una teoría de la justicia social que tenga en cuenta la igual dignidad de todos los seres humanos, aborde la necesidad de contemplar unos principios de justicia a escala mundial, y plantee unos derechos mínimos para todos los habitantes del planeta, en cuya ausencia no se estaría haciendo lo debido por la calidad de vida de todas las personas. Esta experta en ética subraya el papel de las instituciones en el logro de la estabilidad de la sociedad justa y, en particular, en la capacidad de inculcar actitudes y sentimientos correctos en las personas, para que éstas se muestren favorables a cambios de gran alcance en la distribución existente de bienes. 
6.2. La convergencia entre instituciones económicas y políticas, ambas inclusivas, factor de éxito en la búsqueda de la prosperidad y la sostenibilidad en las sociedades

Desde el punto de vista de la comprensión económico-política e histórica de las causas que hacen que unos territorios o países prosperen y otros no a lo largo de la historia, como medio para conseguir el desarrollo y el bienestar, Daron Acemoglu y James A. Robinson (2012) han descubierto la determinante influencia de la interacción entre instituciones políticas y económicas inclusivas -que reparten la riqueza y el poder político de manera amplia y plural- frente a las de tipo extractivo -que ciñen a minorías el poder económico y político- en la consecución de sociedades desarrolladas y democráticas, y, por tanto, más sostenibles y justas.

Para estos autores, las instituciones políticas y económicas inclusivas son la clave de bóveda de un desarrollo sostenible. Es importante tenerlo en cuenta para evitar aquellas fórmulas que han fracasado e intentar replicar las que han tenido éxito a lo largo de la historia, de cara al logro de sociedades económicamente desarrolladas, socialmente cohesionadas y políticamente democráticas. La responsabilidad de la llamada comunidad internacional es alta a la hora de arbitrar los mecanismos que puedan permitir poner en marcha, en el mundo en vías de desarrollo y en el mundo empobrecido, políticas económica y políticamente inclusivas, sostenibles en el tiempo.

\subsection{Insostenibilidad de la globalización asimétrica}

Me parece muy interesante la identificación de las instituciones inclusivas en lo económico y en lo político como factor determinante de cara al progreso, precisamente en un momento en que, según Joseph Stiglitz, vivimos en una 'globalización asimétrica', que, en su actual configuración, no representa los intereses de las mayorías sociales y genera una elevada y creciente desigualdad, al tiempo que vivimos en el mundo occidental, con unos sistemas políticos que tienen importantes déficits de funcionamiento democrático.

Defender, como en su opinión hace ahora el sistema, los intereses del $1 \%$ de la población frente a los del $99 \%$ restante, no es sostenible. Para este autor, 'otro mundo es posible', un mundo, a la vez, más eficiente y justo. Para ello, propone una agenda detallada de actuaciones de política económica y de carácter político, que, en su opinión, harían posible, al mismo tiempo, una economía más próspera y justa.

\subsection{Recuperar el debate sobre una vida deseable}

Desde la economía política y la filosofía, en un momento en el que nadie parece escuchar a nadie, en el que no parece posible habilitar consensos fundamentales, en el que nada es como fue, y en el que el futuro es especialmente incierto, Robert y Edward Skidelsky (2012) proponen retomar lo bueno de las tradiciones económicas y sociales que han generado comportamientos políticos y económicos que han hecho posible el desarrollo económico y alcanzar cotas de justicia social significativas en las democracias más avanzadas, y volver a plantear el sentido de las cosas, las finalidades, el valor de una buena vida, frente a la insensatez de un desarrollo económico orientado por la codicia innata al ser humano y acrecentada por el capitalismo que genera desigualdad y pobreza.

Estos autores nos invitan a replantear los objetivos vitales, huyendo de la insaciabilidad: “¿de qué recursos intelectuales, morales y políticos disponemos aún en las sociedades occidentales para invertir el asalto de la insaciabilidad y redirigir nuestros propósitos hacia la buena vida?", se preguntan.

\subsection{Recuperar el diálogo entre economía y ética}

En una línea de razonamiento similar, Stefano Zamagni, profesor de Economía Política en la Universidad de Bolonia y en la John Hopkins University, plantea en Por una economía del bien común (2008), que es preciso recuperar el diálogo entre la economía y la ética -disciplina que explica por qué algunas interacciones son justas, beneficiosas o deseables, y otras no-. "Algo se puede hacer para humanizar la economía y no sólo se puede, sino que se debe hacer, si es que las personas queremos conquistar esa felicidad a la que inevitablemente aspiramos", argumenta.

Zamagni se niega a admitir que no haya más propuestas económicas que las que tienen por santo y seña el principio del individualismo axiológico, que en el mercado se convierte en la búsqueda del máximo beneficio privado, o las que apuestan por ese colectivismo que acaba ahogando a la persona. Frente a una y otra concepción, propone la 'economía civil', que hace de la persona su centro, y se propone buscar el bien de todas las personas sin exclusión: "Es preciso, pues, optar por un humanismo cívico, por una economía civil”. Subraya la importancia de que las sociedades acepten una estructura triádica, en la convergencia entre el papel del mercado, el del Estado y el de las relaciones de reciprocidad que avancen hacia la fraternidad. En su opinión, "una aldea global que no se construya alrededor de estos tres principios no podrá sobrevivir”. Para llevar a adelante esa economía civil que persigue el bien común, no sólo el privado, es preciso contar con gobernantes y ciudadanos que cultiven las virtudes cívicas. Estas virtudes configuran la mano intangible que, junto a la visible del Estado y la invisible del mercado, permiten una sociedad armoniosa.

\subsection{Resolver el problema de los incentivos a largo plazo}

Parece claro que cualquier intento de articulación de un bien común debe incorporar la perspectiva 
del largo plazo. Como acertadamente señala Daniel Altman, periodista y doctor en Economía por la Universidad de Harvard, en Futuros imperfectos: las doce tendencias asombrosas que remodelarán la economía global (2011), necesitamos resolver el problema de los incentivos a largo plazo de los políticos: "Las soluciones a los grandes problemas a los que se enfrenta la economía global se ven obstaculizadas por la incapacidad de los políticos para contraer compromisos a largo plazo. Si pudiéramos cambiar los incentivos que tienen nuestros líderes y orientarlos más hacia el largo plazo, los resultados serían verdaderamente sensacionales".

Pero, si no logramos este cambio, su vaticinio es negativo: "En las próximas décadas, es probable que la desigualdad aumente, tanto dentro como entre países. Dentro, porque los que tengan riqueza y educación continuarán disfrutando de las mejores oportunidades para explotar las que la integración económica mundial puede crear [...]. Entre ellos, porque fuerzas como el nuevo colonialismo, el calentamiento global y la segmentación del comercio decantarán, más si cabe, el equilibrio de poder y ensancharán la distancia económica entre países ricos y pobres".

Superar estos problemas no resultará fácil, pero será esencial para garantizar todo el crecimiento posible en las próximas décadas. Millones de personas podrán tener una vida más larga y productiva. Y muchos millones más, escapar de la pobreza. No obstante, tal y como están las cosas, nuestros líderes políticos llevan camino de dejar una gran parte de ese crecimiento en el tapete. Tienen todos los incentivos para buscar ganancias a corto plazo, en lugar de beneficios a largo plazo, y actuar cada uno por su cuenta, en lugar de construir coaliciones, señala Altman.

\subsection{Valor y eficacia de la aportación individual en la lucha contra la pobreza}

El profesor de bioética Peter Singer (2012), con datos apabullantes sobre el hambre y la pobreza que parecen escapar a nuestra capacidad de asimilación, tras derribar las barreras conceptuales que conducen a la inacción y mostrar que sí se puede combatir eficazmente la pobreza, sin negar la importancia determinante del cambio institucional de cara a ese fin, subraya el valor y eficacia de la aportación de cada cual-de esos mil millones de personas del mundo rico- para combatir el hambre y la pobreza a escala planetaria, aportación orientada particularmente hacia las organizaciones no gubernamentales de cooperación al desarrollo que han acreditado su eficiencia. La suya es una invitación a cambiar las cosas, y en particular, el problema del hambre y la pobreza extrema, sin esperar a que el sistema cambie, o mientras cambia, o mientras lo vamos cambiando.

\subsection{Trascender el interés individual. Pensar en el bien común}

Quizás, como dice Howard Gardner, catedrático de Cognición y Educación en la Universidad de Harvard, en su libro Verdad, belleza, y bondad reformuladas: la enseñanza de las virtudes en el siglo XXI (2011), la clave sea recordar que lo que nos hace humanos, en el mejor sentido, es nuestro potencial de trascender el interés individual para pensar en lo más sensato para el bienestar general, el bien común: “de ese modo, podemos aportar poderosos modelos que inviten a otros seres humanos a actuar de una manera (cada vez más) responsable”.

Y, añade: “En un mundo difícilmente previsible, ¿cómo podemos prever los efectos - positivos, negativos, imprevistos, con toda probabilidad caóticosde la inteligencia artificial, la nanotecnología, la manipulación genética, el calentamiento global y la posible convergencia de las redes neurales humanas con las 'redes neurales' computacionales en una 'singularidad' sin precedentes?”.

Ante estos nuevos escenarios de incertidumbre, Gardner apela a las virtudes clásicas reformuladas y ofrece un mensaje positivo sobre la capacidad del ser humano de abordar decisiones que no vengan "dictadas por los genes o por los rasgos impersonales de la oferta y la demanda. Podemos ir más allá”.

En esta misma línea, el experto en neurociencias David Eagleman dice en Incógnito: las vidas secretas del cerebro (2013) que: "en un solo centímetro cúbico de tejido cerebral hay tantas conexiones entre neuronas como estrellas en la galaxia de la Vía Láctea" [de 200 a 400 mil millones]. Confiemos, pues, en que la capacidad del cerebro humano, y la interacción de muchos cerebros, sea capaz de articular un nuevo futuro para la humanidad, anclado en la sostenibilidad que da la justicia.

Las ideas expuestas por estos autores nos invitan a considerar la importancia y la factibilidad de modificar el actual estado de cosas en un mundo regido por un sistema económico y orientado por unos valores que, tanto a escala planetaria como en el interior de los países, genera y mantiene crecientes niveles de desigualdad y pobreza, éticamente inaceptables $y$, muy probablemente, económica y políticamente insostenibles. 


\section{Referencias bibliográficas}

ACEMOGLU, D.; y ROBINSON, J. A. (2012): Por qué fracasan los países: los orígenes del poder, la prosperidad y la pobreza, Bilbao, Ediciones Deusto.

ALTMAN, D. (2011): Futuros imperfectos: las doce tendencias asombrosas que remodelarán la economía global, Barcelona, Tendencias Editores.

EAGLEMAN, D. (2013): Incógnito: las vidas secretas del cerebro, Barcelona, Anagrama.

GARDNER, H. (2011) Verdad, belleza y bondad reformuladas: la enseñanza de las virtudes en el siglo XXI, Barcelona, Paidós.

NUSSBAUM, M. C. (2011): Crear capacidades: propuesta para el desarrollo humano, Barcelona, Paidós.
- (2006): Las fronteras de la justicia: consideraciones sobre la exclusión, Barcelona, Paidós.

SINGER, P. (2012): Salvar una vida: cómo terminar con la pobreza, Madrid, Clave Intelectual.

SKIDELSKY, R.; y SKIDELSKY, E. (2012): ¿Cuánto es suficiente?: qué se necesita para una 'buena vida', Barcelona, Crítica.

STIGLITZ, J. E. (2012): El precio de la desigualdad, Madrid, Taurus.

ZAMAGNI, S. (2008) Por una economía del bien común, Madrid, Editorial Ciudad Nueva. 